\title{
Dual inoculation of salt tolerant Bradyrhizobium and Glomus mosseae for improvement of Vigna radiata $L$. cultivation in saline areas of West Bengal, India
}

\author{
Nicky Singh*, Nirmalendu Samajpati, Amal Kanti Paul
}

Department of Botany, University of Calcutta, Kolkata, West Bengal, India; 'Corresponding Author: nickysinghraj@gmail.com

Received 7 September 2011; revised 19 October 2011; accepted 27 October 2011.

\begin{abstract}
This study is aimed as to evaluate the interaction between salt tolerant Bradyrhizobium sp. and Glomus mosseae in the rhizosphere of legume crop Vigna radiata L. under pot culture and field conditions in different saline zones of West Bengal, India. Bradyrhizobium sp. when inoculated alone showed marked increase in number of nodules, root and shoot length, total plant biomass, arbuscular mycorrhizal fungal (AMF) colonization and population etc. when compared with plants inoculated only with AMF. However, when used in combination, the inoculants showed marked change in the above mentioned parameters over single inoculation of both salt tolerant AM fungi and Bradyrhizobium. These results suggest that AMF along with Bradyrhizobium can greatly help in establishment of $V$. radiata $L$. cultivation in the saline soils of West Bengal, India. The increased production of the legume crop could also lead to further benefit of the poor farmers by up lifting their socio-economic conditions with the net profit achieved by cultivating this crop in saline stress condition of West Bengal as a second crop during rabi season.
\end{abstract}

Keywords: Vigna radiata L.; Arbuscular Mycorrhizal Fungi; Bradyrhizobium; Salinity; Glomus mosseae

\section{INTRODUCTION}

Salinization and nutrient depletion are serious and growing problems of agricultural land in different parts of the world [1,2]. Soil salinity inhibits plant growth by reducing the ability of the plant water uptake and ionexcess, which affects the cellular metabolism $[3,4]$. Moreover, it induces nutritional imbalance in plants and thereby reduces the yield of many crops. This ranges from a slight crop loss to complete crop failure depending on the type of crop and severity of the salinity problem. Though several treatments and management practices are available to reduce salt levels in the soil, there are situations where it is either impossible or too costly to attain desirably low soil salinity levels. Reclamation and management of such saline soils are therefore essential to meet the surplus need of food for ever increasing population of developing countries.

In India, coastal saline soils are spreaded over an area of approximately 3.1 million hectare including eight coastal states [5]. Among these, the state of West Bengal has the highest area $\left(820 \times 10^{3}\right.$ hectare $)$ of coastal saline land encompassing five districts namely North 24-Parganas, South 24-Parganas, Haora, East Medinipur and West Medinipur.

The salinity response of legumes in general varies greatly depending on factors like climatic conditions, soil properties, salt tolerance and the stages of crop growth [6-8]. Successful cultivation of legumes can be achieved by the selection and/or development of a salt-tolerant legume/Rhizobium combination although high salinities are known to affect rhizobial activities. The legumeRhizobium symbioses and nodule formation in legumes are more sensitive to salt or osmotic stress. Salinity is reported to affect the infection process by inhibiting root hair growth and decreasing the number of nodule per plant and the amount of $\mathrm{N}_{2}$ fixed per unit weight of nodules. These cause a decrease in the yield of leguminous crops in saline soils due to the lack of the successful symbiosis.

In addition, mutualistic association of arbuscular mycorrhizal fungi (AMF) also improves plant salinity tolerance by virtue of the recognized role of mycorrhizae in plant growth performance [9]. On the contrary, mycorrhizal infection can be suppressed by high salinity depending on the species or the origin of the fungus [10]. However, a synergistic association of arbuscular my- 
corrhizal fungi and rhizobia with leguminous crops has been found to cause an increase in nodulation, nitrogen fixation as well as growth and yield of legumes. Such an effective improvement of plant growth varies with the host genotype. Therefore, the development of host specific, salinity tolerant rhizobia-AMF symbiosis could be an effective approach for the successful cultivation of legume crops in the rabi season as a second crop in the saline tracts.

So far, the response of the pulse crop mung (Vigna radiata L.) to dual inoculation of Rhizobium - arbuscular mycorrhizal fungus and their cultivation under salt stressed conditions have not yet been evaluated under the agro climatic conditions of West Bengal, India. The present investigation is, therefore, an attempt to inoculate Vigna radiata $\mathrm{L}$. with salinity-tolerant rhizobia and AM fungi and to evaluate growth and yield performance of the crop in saline belts of West Bengal which is characterized by mono-crop aman rice cultivation during the kharif season (June-November) only. Cultivation of $V$. radiata $\mathrm{L}$. in these fallow lands as a second crop during the rabi season has also been attempted to improve the socio-economic status of the cultivators of saline zones of West Bengal, India.

\section{MATERIALS AND METHODS}

\subsection{Source of Legume Cultivar and Microbial Culture}

Vigna radiata L., cultivar B-1, the salt tolerant legume was selected during the course of screening of pulse crops for tolerance to salt stress. Seeds of this salt tolerant cultivar were obtained from the Oil and Pulse Seed Research Station, Department of Agriculture, Government of West Bengal, Behrampore, Murshidabad, India and used throughout the present study.

Salt tolerant, streptomycin resistant Bradyrhizobium CAN-11 was isolated from root nodules of salt tolerant cultivar B-1 of V. radiata L. following the method of [11]. The strain was maintained by regular sub culturing on slopes of yeast extract mannitol agar medium. Glomus mosseae (BAS-I) tolerating $\mathrm{NaCl}$ was isolated from saline tracts of West Bengal, India and multiplied in open pot culture of Zea mays L. following the method.

\subsection{Inoculum Development}

The streptomycin resistant, salt tolerant Bradyrhizobium sp. (CAN-11) was grown in yeast extract mannitol agar medium containing $400 \mu \mathrm{g} / \mathrm{ml}$ of streptomycin 48 $96 \mathrm{~h}$ and harvested by centrifugation at $10,000 \times \mathrm{g}$ for 10 min. Inoculum of salt tolerant mycorrhizal complex Glomus mosseae (BAS-I) was prepared in an open-pot culture of Zea mays L. The soil of the pot was inoculated with spores, mycelia of G. mosseae (BAS-I) and pieces of infected Zea mays roots. After 50 days of growth of Zea mays, the soil of the pots was taken out, properly dried in an open air and stored in polypackets for future use.

\subsection{Cultivation in Earthen Pots}

The earthen ware pots ( $15 \mathrm{~cm}$ dia.) filled with $2 \mathrm{~kg}$ saline soils of respective saline zones of West Bengal and autoclaved twice at $121^{\circ} \mathrm{C}$ for $1 \mathrm{~h}$. Seeds of $\mathrm{V}$. radiata $\mathrm{L}$. cultivar B-1 were surface sterilized in ethanol: $\mathrm{H}_{2} \mathrm{O}_{2}$ (1:1) for $3 \mathrm{~min}$, washed with sterile distilled water and germinated. Five healthy germinated seeds per pot were sown during March/April and the pots were covered with cellophane topped paper cylinder. After two weeks, the tops were removed and the plants were transferred to glass house maintained with a day/night temperature of approximately $28^{\circ} \mathrm{C} / 20^{\circ} \mathrm{C}, 75 \%$ - $85 \%$ relative humidity (RH) and a photoperiod of 12 - 13 h. After 7 days, each pot was inoculated with $1 \mathrm{~mL}$ of bacterial suspension $\left(10^{8}\right.$ cells $\left.\mathrm{mL}^{-1}\right)$ [12] and/or with $10 \mathrm{~g}$ of mycorrhizal inoculum (50 propagules $\mathrm{g}^{-1}$ of soil) [13].

Four combinations of inoculation were used: 1) Bradyrhizobium (CAN-11), 2) Glomus mosseae (BAS-I), 3) Bradyrhizobium (CAN-11) + Glomus mosseae (BAS-I) and 4) uninoculated pots served as control. Five replications per inoculation treatment were prepared. The plants were watered at a regular interval of 2 days. Pot soils were also supplemented with a basal nutrient solution containing (in $\mathrm{mol} \cdot \mathrm{m}^{-3}$ ): $\mathrm{CaCl}_{2}, 0.25 ; \mathrm{KCl}, 0.15 ; \mathrm{K}_{2} \mathrm{HPO}_{4}$, 0.06; $\mathrm{MgSO}_{4}, 0.25$; FeEDTA. 0.12; and (in $\mathrm{mol} \cdot \mathrm{m}^{-3}$ ): $\mathrm{H}_{3} \mathrm{BO}_{4}, 11.5 ; \mathrm{MgSO}_{4}, 0.9 ; \mathrm{ZnSO}_{4}, 0.2 ; \mathrm{CuSO}_{4}, 0.07$; and $\mathrm{H}_{2} \mathrm{MoO}_{4}, 0.3$. During experiments with AM fungi, $\mathrm{P}$ was omitted. Plants were harvested during May/June and the growth parameters were evaluated.

\subsection{Cultivation in Field Plots}

Field experiments were conducted in random block design (RBD) with three replications. The plot size was $5 \mathrm{~m} \times 4 \mathrm{~m}$ with spacing of $30 \mathrm{~cm} \times 10 \mathrm{~cm}$ between rows and crop. Seeds were inoculated with salt tolerant Bradyrhizobium (CAN-11) and Glomus mosseae (BAS-I) inoculants by mixing thoroughly with the slurry of inoculants. Prior to sowing of seeds, field soil was provided with fresh culture of mixed inoculants on the surface layer (2 - $3 \mathrm{~cm}$ deep) and mixed thoroughly with ladder ploughing. The fertilizer was added at the rate of $\mathrm{N}: \mathrm{K}: \mathrm{P}$ at 20:60:20 kg/ha, but during AMF experiments $\mathrm{P}$ was omitted.

Seeds were sown in March/April by broadcasting at the rate of $15 \mathrm{~kg} / \mathrm{ha}$. Three irrigations were given: first at pre-sowing, second at flowering/ pod initiations and the 
third one during grain setting stage. Weeding was done regularly as and when required and the crop was harvested during May/June.

\subsection{Estimation of Plat Growth}

Plants were harvested after 90 days of growth. The growth of $V$. radiata L. was estimated by measuring the length of the plant aerial part and the biomass produced by shoots and roots. Shoots and roots were dried separately at $80^{\circ} \mathrm{C}$ for $48 \mathrm{~h}$ and their dry weights were recorded.

Relative growth rate $(R G R)$ for total plant $\left(R G R_{t}\right)$, shoot $\left(R G R_{S}\right)$, and root $\left(R G R_{r}\right)$ were calculated on the basis of days of growth and expressed as dry weight of plants using the following formula:

$$
R G R_{i}=\left(\operatorname{In} W t_{t}-\operatorname{In} W t_{o}\right) / t_{t}-t_{o}
$$

where $i=$ variable used (total plant shoot or root dry $w t$ ) to measure RGR $\left(\right.$ day $\left.^{-1}\right) ; t_{t}=$ is the total period of growth (day) from germination; $t_{o}=$ is the initial period of growth of 45 days from germination; $W t_{t}=$ is plant dry weight (total shoot or root) at the end of the experimenttal period (90 day); $W t_{o}=$ is plant dry weight at the beginning of the experimental period (45 day).

\subsection{Root Colonization and Spore Count of AM Fungi}

Root colonization by AM fungi was studied following the method as described by [14] Colonization of AM fungi was determined by evaluating percentage of root segments containing arbuscules and Vesicles using gridline intercept method of [15].

AM fungal spores were recovered from rhizospheric soil by wet sieving followed by sucrose gradient centrifugation method of [16]. Spores were counted under $\times 35$ magnification in a dissecting microscope and the density (SD) was expressed as the number of spore's $\mathrm{g}^{-1}$ dry soil.

\subsection{Socioeconomic Study}

A door to door survey on social stratification, population size and annual income of families in some selected villages of Kakdwip areas of South 24-Parganas were conducted.

\subsection{Statistical Analysis}

All data were subjected to analysis of variance (ANOVA) followed by Duncan's multiple range list [17]. Percentage data were arcsine - transformed before a statistical analysis.

\section{RESULTS}

In pot culture experiments with saline soils from South and North 24-Parganas and East Medinipur districts of West Bengal growth of inoculated V. radiata $\mathrm{L}$. cultivar B-1 was in general higher than the non-inoculated ones. When applied as single inoculum, performance of Bradyrhizobium CAN-11 was much better than G. mosseae BAS-I. At the same time, a significant improvement of growth was noticed for the dual inoculation of CAN-11 and BAS-I (Table 1). All the growth parameters studied i.e. plant height, shoot and root length, shoot and root dry/fresh weight and shoot/root ratio showed noticeable improvement due to dual inoculation. In general, growth of the crop was better in South 24-Parganas compared to North 24-Parganas and East Medinipur districts of West Bengal, India.

The relative growth rate $(R G R)$ for total plant $\left(R G R_{t}\right)$, shoot $\left(R G R_{s}\right)$ and root $\left(R G R_{r}\right)$ were determined within a period of 90 days and it was found maximum in North 24-Parganas during double inoculation of Bradyrhizobium CAN-11 and G. mosseae BAS-I (Figure 1).

The number of nodules per plant after three months of inoculation depended on the microsymbionts utilized. The no. of nodules per plant varied between 29 (treatment with CAN-11), 25 (treatment with BAS-I) and 34 (treatment with BAS-I + CAN-11) in North 24-Pargana soil. In South 24-pargana soil it was maximum with 33 nodules plant ${ }^{-1}$ with treatment of BAS-I and CAN-11; E. Medinipur has the lowest i.e. 29 nodules plant ${ }^{-1}$ with treatment of BAS-I and CAN-11 (Figure 2) Fresh and dry weights of nodules were in relevance with number of nodules.

The level of mycorrhizal infection in roots of $\mathrm{V}$. radiata L. cultivar B-I appeared to be less sensitive to $\mathrm{NaCl}$ and the mycorrhizal infection was maximum in all three districts of West Bengal with double inoculation (BAS-I + CAN-11) when compared to single inoculation by BAS-I or CAN-11 (Figure 3(a)). Similarly, the AM spore population in soil of all three districts was maximum during dual inoculation experiments. However, highest spore population was recorded in North 24-Parganas of West Bengal (Figure 3(b)).

Field trial of $V$. radiata $\mathrm{L}$. was made under random block design using dual inoculation of Bradyrhizobium CAN-11 and G. mosseae BAS-I. Cultivations were conducted in three different districts viz. North 24-Parganas (Deuli, Kharampur and Saimalpur), South 24-Parganas (Basanti, Canning and Kakdwip) and East Medinipur (Kanthi and Tamluk) during 2005 and 2006. Growth performance of the legume was in general superior in South 24-Parganas than in North 24-Parganas and E. Medinipur. In South 24-Parganas alone performance was best in Basanti was followed by Canning and Kakdwip 
Table 1. Effect of salt tolerant Bradyrhizobium CAN-11 and G. mosseae BAS-1 on the growth of Vigna radiata cv. B-1 in pot culture.

\begin{tabular}{|c|c|c|c|c|}
\hline \multirow{2}{*}{ Source of soil } & \multirow{2}{*}{ Control (uninoculated soil) } & \multicolumn{3}{|c|}{ Soil inoculants } \\
\hline & & CAN-11 & BAS-I & CAN-11 + BAS-I \\
\hline \multicolumn{5}{|l|}{ South 24-Parganas ${ }^{\mathrm{A}}$} \\
\hline Plant height $(\mathrm{cm})$ & $55.90 \pm 0.35^{\mathrm{e}}$ & $59.40 \pm 0.34^{\mathrm{e}}$ & $58.90 \pm 0.32^{\mathrm{ab}}$ & $62.04 \pm 0.30^{\mathrm{e}}$ \\
\hline Plant biomass, dry (g) & $3.20 \pm 0.12^{\mathrm{b}}$ & $3.46 \pm 0.10^{\mathrm{bc}}$ & $3.40 \pm 0.12^{\mathrm{d}}$ & $3.54 \pm 0.14^{\mathrm{d}}$ \\
\hline Shoot length $(\mathrm{cm})$ & $44.80 \pm 0.24^{\mathrm{d}}$ & $46.80 \pm 0.12^{\mathrm{c}}$ & $46.20 \pm 0.36^{\mathrm{e}}$ & $49.80 \pm 0.42^{\mathrm{f}}$ \\
\hline Shoot weight, dry (g) & $2.44 \pm 0.10^{\mathrm{a}}$ & $2.88 \pm 0.10^{\mathrm{d}}$ & $2.81 \pm 0.12^{\mathrm{c}}$ & $2.98 \pm 0.16^{\mathrm{b}}$ \\
\hline Root length (cm) & $11.10 \pm 0.12^{\mathrm{d}}$ & $12.60 \pm 0.20^{\mathrm{e}}$ & $12.42 \pm 0.14^{\mathrm{d}}$ & $13.10 \pm 0.20^{\mathrm{d}}$ \\
\hline Root weight, dry (g) & $0.76 \pm 0.06^{\mathrm{f}}$ & $0.86 \pm 0.04^{\mathrm{b}}$ & $0.82 \pm 0.04^{\mathrm{a}}$ & $0.94 \pm 0.08^{c}$ \\
\hline Shoot/Root ratio (length) & $4.03 \pm 0.14^{\mathrm{c}}$ & $3.71 \pm 0.08^{\mathrm{d}}$ & $3.72 \pm 0.12^{\mathrm{b}}$ & $3.80 \pm 0.12^{\mathrm{b}}$ \\
\hline Yield of grains $(\mathrm{g})$ & $1.84 \pm 0.14^{\mathrm{e}}$ & $2.89 \pm 0.30^{\mathrm{d}}$ & $2.71 \pm 0.22^{\mathrm{a}}$ & $3.70 \pm 0.24^{\mathrm{c}}$ \\
\hline \multicolumn{5}{|l|}{ North 24-Parganas ${ }^{\mathrm{B}}$} \\
\hline Plant height $(\mathrm{cm})$ & $58.00 \pm 0.34^{\mathrm{d}}$ & $60.60 \pm 0.36^{\mathrm{a}}$ & $59.04 \pm 0.28^{\mathrm{a}}$ & $63.26 \pm 0.40^{\mathrm{b}}$ \\
\hline Plant biomass, dry (g) & $3.58 \pm 0.08^{\mathrm{c}}$ & $3.77 \pm 0.12^{\mathrm{d}}$ & $3.64 \pm 0.12^{\mathrm{d}}$ & $4.14 \pm 0.06^{\mathrm{c}}$ \\
\hline Shoot length $(\mathrm{cm})$ & $46.60 \pm 0.42^{\mathrm{bc}}$ & $47.40 \pm 0.40^{\mathrm{b}}$ & $47.20 \pm 0.48^{\mathrm{c}}$ & $49.40 \pm 0.42^{\mathrm{e}}$ \\
\hline Shoot weight, dry (g) & $2.64 \pm 0.08^{\mathrm{d}}$ & $2.67 \pm 0.14^{\mathrm{d}}$ & $2.66 \pm 0.12^{\mathrm{e}}$ & $2.86 \pm 0.12^{\mathrm{a}}$ \\
\hline Root length $(\mathrm{cm})$ & $11.40 \pm 0.12^{\mathrm{ef}}$ & $13.20 \pm 0.24^{\mathrm{ef}}$ & $12.84 \pm 0.18^{\mathrm{d}}$ & $13.86 \pm 0.30^{\mathrm{b}}$ \\
\hline Root weight, dry (g) & $0.94 \pm 0.04^{\mathrm{d}}$ & $1.10 \pm 0.04^{\mathrm{c}}$ & $0.98 \pm 0.02^{\mathrm{b}}$ & $1.28 \pm 0.08^{\mathrm{cd}}$ \\
\hline Shoot/Root ratio (length) & $4.88 \pm 0.14^{\mathrm{c}}$ & $3.59 \pm 0.10^{\mathrm{d}}$ & $3.67 \pm 0.06^{\mathrm{c}}$ & $3.56 \pm 0.12^{\mathrm{d}}$ \\
\hline Yield of grains $(\mathrm{g})$ & $2.24 \pm 0.06^{\mathrm{d}}$ & $3.89 \pm 0.08^{\mathrm{a}}$ & $3.09 \pm 0.06^{\mathrm{d}}$ & $4.50 \pm 0.10^{\mathrm{a}}$ \\
\hline \multicolumn{5}{|l|}{ East Medinipur $^{\mathrm{C}}$} \\
\hline Plant height (cm) & $68.30 \pm 0.48^{\mathrm{e}}$ & $71.60 \pm 0.52^{\mathrm{a}}$ & $70.50 \pm 0.48^{\mathrm{a}}$ & $75.00 \pm 0.54^{\mathrm{c}}$ \\
\hline Plant biomass, dry (g) & $2.10 \pm 0.12^{\mathrm{b}}$ & $2.54 \pm 0.12^{\mathrm{d}}$ & $2.28 \pm 0.14^{\mathrm{c}}$ & $2.86 \pm 0.16^{\mathrm{e}}$ \\
\hline Shoot length $(\mathrm{cm})$ & $53.60 \pm 0.34^{\mathrm{d}}$ & $55.10 \pm 0.32^{\mathrm{f}}$ & $54.40 \pm 0.36^{\mathrm{e}}$ & $57.20 \pm 0.32^{\mathrm{b}}$ \\
\hline Shoot weight, dry (g) & $1.78 \pm 0.18^{\mathrm{b}}$ & $2.10 \pm 0.16^{\mathrm{a}}$ & $1.82 \pm 0.14^{\mathrm{d}}$ & $2.34 \pm 0.16^{\mathrm{a}}$ \\
\hline Root length (cm) & $14.70 \pm 0.22^{\mathrm{d}}$ & $16.50 \pm 0.28^{\mathrm{b}}$ & $16.10 \pm 0.24^{\mathrm{b}}$ & $17.80 \pm 0.28^{\mathrm{d}}$ \\
\hline Root weight, dry (g) & $0.42 \pm 0.06^{\mathrm{f}}$ & $0.49 \pm 0.08^{\mathrm{c}}$ & $0.46 \pm 0.06^{\mathrm{c}}$ & $0.52 \pm 0.08^{\mathrm{c}}$ \\
\hline Shoot/Root ratio (length) & $3.64 \pm 0.12^{\mathrm{c}}$ & $3.64 \pm 0.14^{\mathrm{d}}$ & $3.37 \pm 0.10^{\mathrm{a}}$ & $3.21 \pm 0.14^{\mathrm{d}}$ \\
\hline Yield of grains (g) & $3.16 \pm 0.32^{\mathrm{d}}$ & $4.44 \pm 0.32^{\mathrm{d}}$ & $3.61 \pm 0.36^{\mathrm{c}}$ & $5.21 \pm 0.34^{\mathrm{b}}$ \\
\hline
\end{tabular}

Soils of experimental sites were thoroughly mixed in equal proportion and used in pots. Soil salinity: ${ }^{\mathrm{A}}=7.5\left(\mathrm{dSm}^{-1}\right),{ }^{\mathrm{B}}=6.5\left(\mathrm{dSm}^{-1}\right)$ and ${ }^{\mathrm{C}}=7.2\left(\mathrm{dSm}{ }^{-1}\right)$. ${ }_{a, b, b, d, e, f}$ Mean data in each vertical row followed by different letters are significantly different $(P \leq 0.05)$ as per Duncan's Multiple Range Test $(n=5)$. Values indicate mean of five replicates $\pm \mathrm{S}$ E.

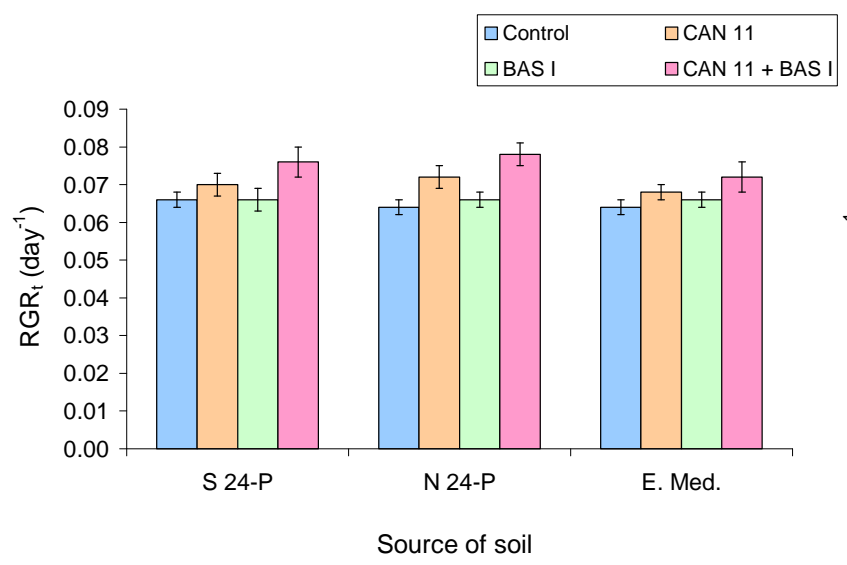

(a)

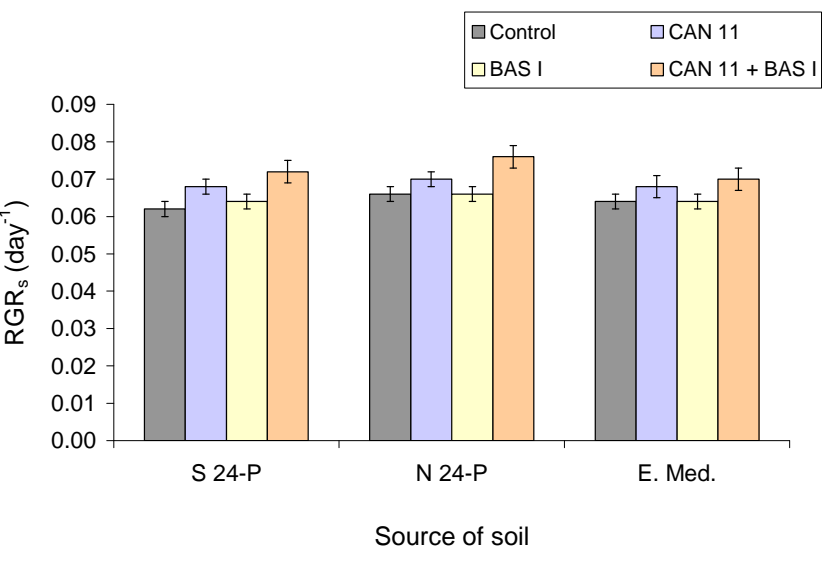

(b) 


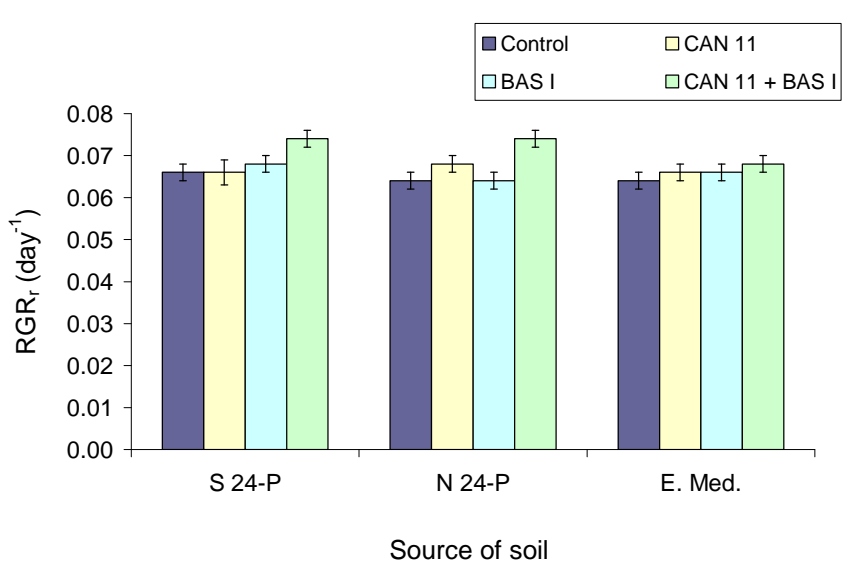

(c)

Figure 1. Relative growth rate of total plant $R G R_{t}(\mathrm{a})$, total shoot $R G R_{\mathrm{s}}(\mathrm{b})$ and total root $R G R_{r}(\mathrm{c})$ of $V$. radiata cv. B-1 inoculated with Bradyrhizobium CAN-11 and or G. mosseae BAS- I in pot culture. S 24-P = South 24-Parganas, N 24-P = North 24-Parganas and E. Med = East Medinipur.

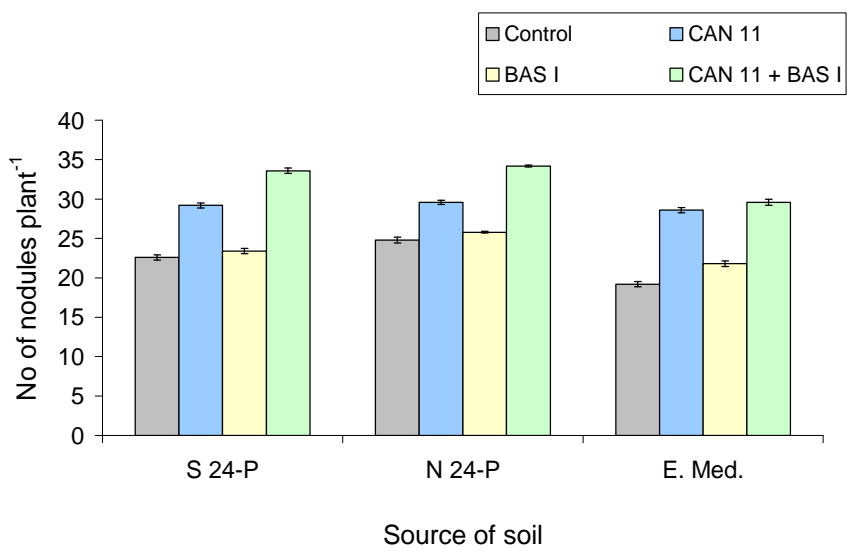

(a)
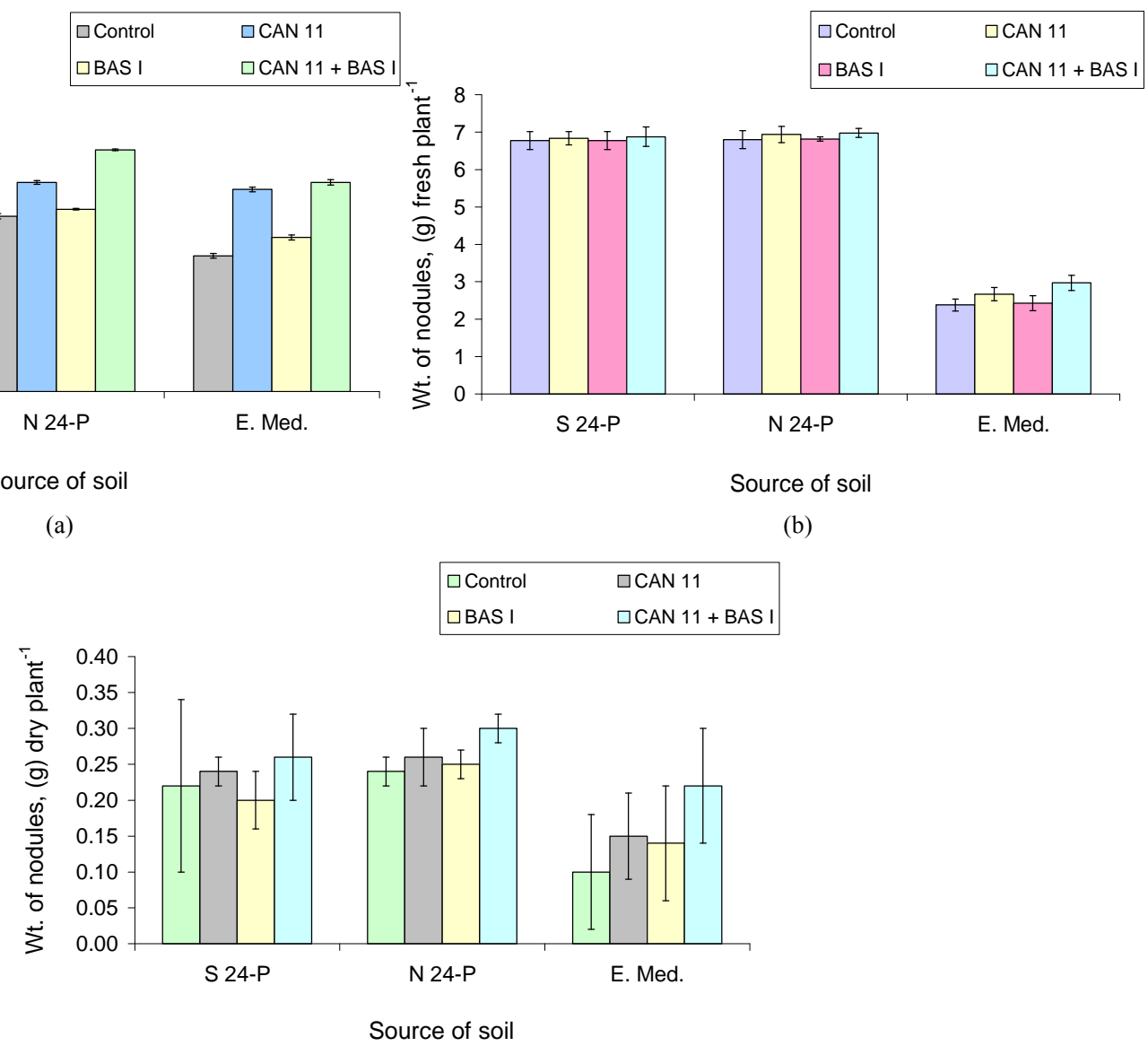

(c)

Figure 2. Effect of salt tolerant Bradyrhizobium CAN-11 and G. mosseae BAS-I inoculation on number of nodules plant ${ }^{-1}$ (a), fresh wt. of nodules plant ${ }^{-1}$ (b) and dry wt of nodules plant ${ }^{-1}$ (c) of $V$. radiata cv. B-1 in pot culture. S 24-P $=$ South 24-Parganas, N 24-P = North 24-Parganas and E. Med = East Medinipur.

(Table 2). In Table 3 we find that growth was maximum in Kharampur followed by Deuli and Saimalpur in North
24-Parganas. Similarly in Table 4 Tamluk was better than Kanthi of East Medinipur districts. 


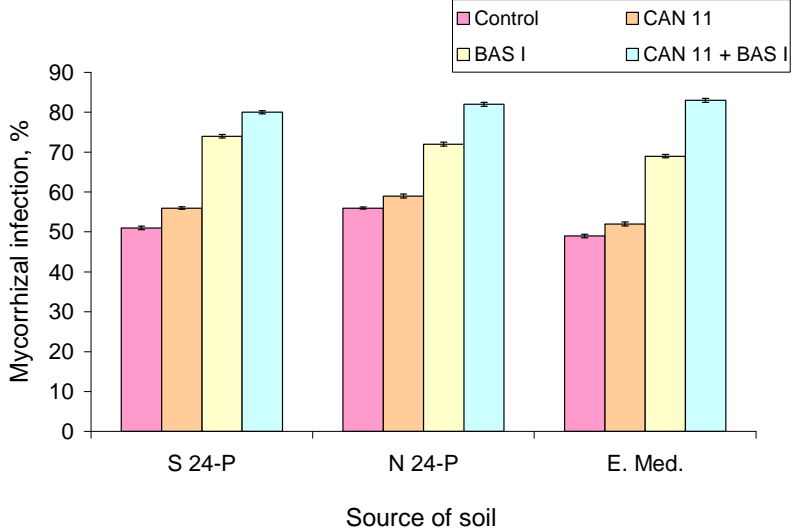

(a)

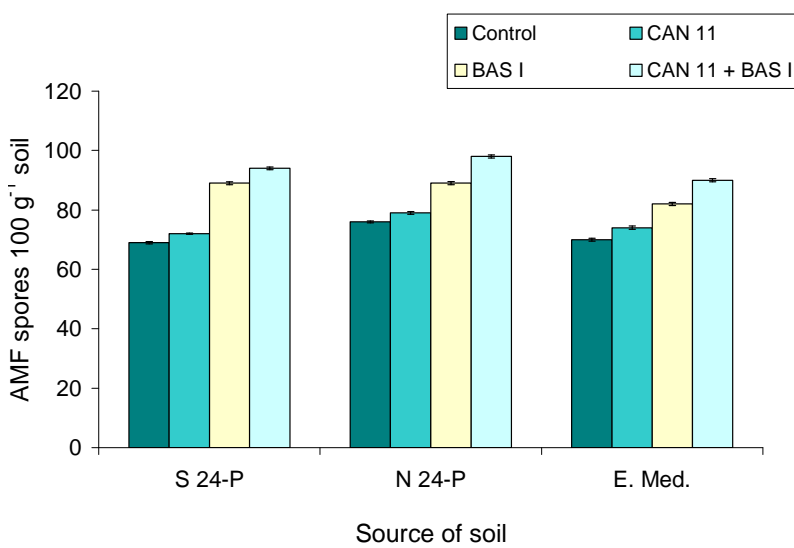

(b)

Figure 3. Incidence of mycorrhizal infection and population of AMF spores during growth of $V$. radiata cv. B-1 inoculated with Bradyrhizobium CAN-11 and or G. mosseae BAS-I in pot culture of S 24-P = South 24-Parganas, N 24-P = North 24-Parganas and E. Med = East Medinipur.

Table 2. Effect of inoculation of salt tolerant Bradyrhizobium CAN -11 and salt tolernt G. mosseae BAS-I on the growth of V. radiata cv. B-1 in different experimental fields of South 24-Parganas during 2005 and 2006.

\begin{tabular}{|c|c|c|c|c|c|c|}
\hline \multirow{3}{*}{ Growth characteristics/plant ${ }^{-1}$} & \multicolumn{6}{|c|}{ Experimental fields of South 24-Parganas } \\
\hline & \multicolumn{2}{|c|}{ Basanti } & \multicolumn{2}{|c|}{ Canning } & \multicolumn{2}{|c|}{ Kakdwip } \\
\hline & 2005 & 2006 & 2005 & 2006 & 2005 & 2006 \\
\hline Plant height $(\mathrm{cm})$ & $69.00 \pm 4.50^{\mathrm{a}}$ & $70.50 \pm 4.52^{\mathrm{c}}$ & $68.60 \pm 4.98^{\mathrm{a}}$ & $69.40 \pm 4.46^{\mathrm{a}}$ & $64.00 \pm 4.42^{\mathrm{d}}$ & $64.80 \pm 4.44^{\mathrm{a}}$ \\
\hline Total plant biomass (g), fresh & $20.80 \pm 2.36^{\mathrm{c}}$ & $21.20 \pm 2.34^{\mathrm{b}}$ & $19.80 \pm 2.32^{\mathrm{b}}$ & $20.90 \pm 2.36^{\mathrm{c}}$ & $20.10 \pm 2.32^{\mathrm{e}}$ & $20.40 \pm 2.28^{\mathrm{b}}$ \\
\hline Total plant biomass (g), dry & $4.30 \pm 0.24^{\mathrm{d}}$ & $4.20 \pm 0.26^{\mathrm{e}}$ & $4.16 \pm 0.18^{c}$ & $4.32 \pm 0.16^{\mathrm{d}}$ & $4.14 \pm 0.20^{\mathrm{f}}$ & $4.18 \pm 0.22^{\mathrm{c}}$ \\
\hline Shoot length (cm) & $56.20 \pm 3.48^{\mathrm{e}}$ & $56.80 \pm 3.46^{\mathrm{d}}$ & $55.40 \pm 3.50^{\mathrm{d}}$ & $56.30 \pm 3.54^{\mathrm{f}}$ & $52.10 \pm 3.44^{\mathrm{b}}$ & $52.40 \pm 3.46^{\mathrm{d}}$ \\
\hline Shoot weight (g), fresh & $16.12 \pm 2.20^{\mathrm{b}}$ & $16.30 \pm 2.22^{\mathrm{a}}$ & $15.90 \pm 2.18^{\mathrm{f}}$ & $16.10 \pm 2.16^{\mathrm{b}}$ & $15.60 \pm 2.20^{\mathrm{e}}$ & $15.62 \pm 2.28^{\mathrm{e}}$ \\
\hline Shoot weight (g), dry & $3.28 \pm 0.12^{\mathrm{a}}$ & $3.31 \pm 0.10^{\mathrm{b}}$ & $3.10 \pm 0.14^{\mathrm{a}}$ & $3.12 \pm 0.12^{\mathrm{c}}$ & $3.06 \pm 0.14^{\mathrm{d}}$ & $3.07 \pm 0.16^{\mathrm{b}}$ \\
\hline Root length (cm) & $12.80 \pm 1.26^{\mathrm{c}}$ & $13.70 \pm 1.28^{\mathrm{e}}$ & $13.20 \pm 1.24^{\mathrm{b}}$ & $13.10 \pm 1.24^{\mathrm{d}}$ & $11.90 \pm 1.22^{\mathrm{e}}$ & $12.40 \pm 1.20^{\mathrm{d}}$ \\
\hline Root weight (g), fresh & $4.68 \pm 0.10^{\mathrm{d}}$ & $4.90 \pm 0.18^{\mathrm{f}}$ & $3.90 \pm 0.16^{\mathrm{d}}$ & $4.80 \pm 0.18^{\mathrm{e}}$ & $4.50 \pm 0.20^{\mathrm{b}}$ & $4.78 \pm 0.22^{\mathrm{a}}$ \\
\hline Root weight (g), dry & $1.02 \pm 0.08^{\mathrm{a}}$ & $0.89 \pm 0.06^{\mathrm{b}}$ & $1.06 \pm 0.08^{\mathrm{e}}$ & $1.20 \pm 0.10^{\mathrm{a}}$ & $1.08 \pm 0.08^{\mathrm{cd}}$ & $1.11 \pm 0.14^{\mathrm{c}}$ \\
\hline Shoot/Root ratio (length) & $4.39 \pm 2.76^{b}$ & $4.14 \pm 2.70^{\mathrm{c}}$ & $4.19 \pm 2.82^{c}$ & $4.29 \pm 2.85^{\mathrm{c}}$ & $4.37 \pm 2.81^{\mathrm{d}}$ & $4.22 \pm 2.88^{\mathrm{b}}$ \\
\hline No. of branches & $4.92 \pm 0.80^{\mathrm{c}}$ & $4.96 \pm 1.22^{\mathrm{d}}$ & $4.84 \pm 1.24^{\mathrm{d}}$ & $4.90 \pm 1.24^{\mathrm{b}}$ & $4.70 \pm 1.18^{\mathrm{de}}$ & $4.74 \pm 1.22^{\mathrm{d}}$ \\
\hline No. of pods & $17.60 \pm 2.32^{\mathrm{d}}$ & $18.60 \pm 2.32^{\mathrm{e}}$ & $16.80 \pm 2.34^{\mathrm{b}}$ & $17.40 \pm 2.36^{\mathrm{d}}$ & $16.60 \pm 2.38^{\mathrm{ef}}$ & $17.00 \pm 2.32^{\mathrm{e}}$ \\
\hline No. of seeds pod ${ }^{-1}$ & $8.40 \pm 1.24^{\mathrm{e}}$ & $8.50 \pm 1.26^{\mathrm{a}}$ & $6.80 \pm 1.20^{\mathrm{a}}$ & $7.20 \pm 1.18^{\mathrm{c}}$ & $6.60 \pm 1.20^{\mathrm{a}}$ & $7.40 \pm 1.18^{\mathrm{b}}$ \\
\hline Weight of seeds (100 nos.) & $3.18 \pm 0.12^{\mathrm{a}}$ & $3.20 \pm 0.12^{\mathrm{b}}$ & $3.10 \pm 0.14^{\mathrm{cd}}$ & $3.12 \pm 0.16^{\mathrm{a}}$ & $3.12 \pm 0.12^{\mathrm{bc}}$ & $3.12 \pm 0.14^{\mathrm{c}}$ \\
\hline No. of nodule & $34.20 \pm 4.42^{\mathrm{bc}}$ & $35.10 \pm 3.42^{\mathrm{c}}$ & $32.20 \pm 3.44^{\mathrm{d}}$ & $33.40 \pm 3.46^{\mathrm{b}}$ & $31.80 \pm 3.38^{\mathrm{d}}$ & $32.60 \pm 3.34^{\mathrm{d}}$ \\
\hline Weight of nodules (g), fresh & $7.10 \pm 1.24^{\mathrm{c}}$ & $7.12 \pm 1.22^{\mathrm{d}}$ & $6.98 \pm 1.32^{\text {ef }}$ & $6.98 \pm 1.34^{\mathrm{c}}$ & $6.60 \pm 1.20^{\mathrm{b}}$ & $6.70 \pm 1.28^{\mathrm{e}}$ \\
\hline Weight of nodules (g), dry & $0.34 \pm 0.06^{\text {cd }}$ & $0.34 \pm 0.60^{\mathrm{f}}$ & $0.30 \pm 0.08^{\mathrm{f}}$ & $0.30 \pm 0.08^{\mathrm{d}}$ & $0.28 \pm 0.08^{\mathrm{c}}$ & $0.29 \pm 0.06^{\mathrm{a}}$ \\
\hline Population of AMF (spores $100 \mathrm{~g}^{-1}$ soil) & $106 \pm 4.2^{\mathrm{e}}$ & $108 \pm 2.12^{\mathrm{a}}$ & $98 \pm 4.46^{\mathrm{d}}$ & $98 \pm 1.22^{\mathrm{e}}$ & $96 \pm 4.18^{\mathrm{a}}$ & $98 \pm 4.14^{\mathrm{b}}$ \\
\hline Colonization of roots $(\%)$ & $82 \pm 3.8^{\mathrm{b}}$ & $82 \pm 3.62^{\mathrm{c}}$ & $68 \pm 2.86^{\mathrm{cd}}$ & $70 \pm 4.54^{\mathrm{f}}$ & $66 \pm 3.1^{\mathrm{d}}$ & $70 \pm 4.26^{\mathrm{c}}$ \\
\hline Days of maturity & $74 \pm 5^{\mathrm{d}}$ & $73 \pm 4^{\mathrm{b}}$ & $76 \pm 4^{\mathrm{d}}$ & $73 \pm 5^{\mathrm{a}}$ & $78 \pm 4^{\mathrm{b}}$ & $77 \pm 5^{\mathrm{d}}$ \\
\hline Yield of grain $\left(\mathrm{kg} \cdot \mathrm{ha}^{-1}\right)$ & $560 \pm 21^{\mathrm{c}}$ & $568 \pm 20^{\mathrm{d}}$ & $570 \pm 25^{\mathrm{a}}$ & $575 \pm 18^{\mathrm{b}}$ & $540 \pm 14^{\mathrm{e}}$ & $548 \pm 18^{\mathrm{e}}$ \\
\hline$R G R_{t}\left(\right.$ day $\left.^{-1}\right)$ & $0.076 \pm 0.002^{\mathrm{d}}$ & $0.078 \pm 0.002^{\mathrm{e}}$ & $0.066 \pm 0.002^{\mathrm{c}}$ & $0.068 \pm 0.002^{\mathrm{c}}$ & $0.066 \pm 0.002^{\mathrm{a}}$ & $0.067 \pm 0.003^{\mathrm{c}}$ \\
\hline$R G R_{s}\left(\right.$ day $\left.^{-1}\right)$ & $0.074 \pm 0.002^{\mathrm{b}}$ & $0.076 \pm 0.002^{\mathrm{c}}$ & $0.066 \pm 0.002^{\mathrm{e}}$ & $0.068 \pm 0.002^{\mathrm{e}}$ & $0.066 \pm 0.002^{\mathrm{d}}$ & $0.068 \pm 0.002^{\mathrm{b}}$ \\
\hline$R G R_{r}\left(\right.$ day $\left.^{-1}\right)$ & $0.074 \pm 0.003^{\mathrm{a}}$ & $0.075 \pm 0.002^{\mathrm{d}}$ & $0.066 \pm 0.002^{\mathrm{d}}$ & $0.068 \pm 0.002^{\mathrm{d}}$ & $0.064 \pm 0.002^{\mathrm{c}}$ & $0.068 \pm 0.002^{\mathrm{a}}$ \\
\hline
\end{tabular}

Values indicate mean of five replicates $\pm \mathrm{SE}$. ${ }^{\mathrm{a}, \mathrm{b}, \mathrm{c}, \mathrm{d}, \mathrm{e}, \mathrm{f}}$ Mean data in each vertical row followed by different letters are significantly different $(\mathrm{P} \leq 0.05)$ as per Duncan's Multiple Range Test $(\mathrm{n}=5) . R G R_{t}, R G R_{s}$ and $R G R_{r}$ are Relative growth rate of total plant, shoot and root respectively determined within a period of growth of 45 days. 
Table 3. Effect of inoculation of salt tolerant Bradyrhizobium CAN-11 and G. mosseae BAS-I on the growth of V. radiata cv. B-1 in different experimental fields of North 24-Parganas during 2005 and 2006.

\begin{tabular}{|c|c|c|c|c|c|c|}
\hline \multirow{3}{*}{ Growth characteristics/plant ${ }^{-1}$} & \multicolumn{6}{|c|}{ Experimental fields of North 24-Parganas } \\
\hline & \multicolumn{2}{|c|}{ Deuli } & \multicolumn{2}{|c|}{ Kharampur } & \multicolumn{2}{|c|}{ Saimalpur } \\
\hline & 2005 & 2006 & 2005 & 2006 & 2005 & 2006 \\
\hline Plant height (cm) & $66.80 \pm 4.62^{\mathrm{a}}$ & $67.20 \pm 4.58^{\mathrm{c}}$ & $68.10 \pm 4.48^{\mathrm{c}}$ & $68.70 \pm 4.52^{\mathrm{c}}$ & $64.40 \pm 4.60^{\mathrm{a}}$ & $66.10 \pm 4.64^{\mathrm{a}}$ \\
\hline Total plant biomass $(\mathrm{g})$, fresh & $23.20 \pm 2.28^{b}$ & $23.60 \pm 2.26^{\mathrm{d}}$ & $24.50 \pm 2.30^{\mathrm{d}}$ & $24.90 \pm 2.32^{\mathrm{d}}$ & $22.60 \pm 0.30^{\mathrm{b}}$ & $23.00 \pm 2.34^{\mathrm{b}}$ \\
\hline Total plant biomass (g), dry & $4.42 \pm 0.18^{\mathrm{c}}$ & $4.43 \pm 0.16^{\mathrm{a}}$ & $4.50 \pm 0.26^{\mathrm{f}}$ & $4.52 \pm 0.22^{\mathrm{a}}$ & $3.92 \pm 0.18^{\mathrm{d}}$ & $4.24 \pm 0.24^{\mathrm{d}}$ \\
\hline Shoot length $(\mathrm{cm})$ & $52.80 \pm 3.60^{\mathrm{d}}$ & $53.10 \pm 3.58^{\mathrm{b}}$ & $53.70 \pm 3.62^{\mathrm{e}}$ & $54.10 \pm 3.56^{\mathrm{b}}$ & $51.10 \pm 3.60^{\mathrm{c}}$ & $52.40 \pm 3.62^{\mathrm{e}}$ \\
\hline Shoot weight $(\mathrm{g})$, fresh & $16.70 \pm 2.28^{\mathrm{e}}$ & $16.90 \pm 2.36^{\mathrm{c}}$ & $17.00 \pm 2.34^{\mathrm{a}}$ & $17.50 \pm 2.28^{\mathrm{c}}$ & $15.60 \pm 2.30^{\mathrm{e}}$ & $15.80 \pm 2.32^{\mathrm{a}}$ \\
\hline Shoot weight (g), dry & $3.10 \pm 0.16^{\mathrm{bc}}$ & $3.12 \pm 0.18^{\mathrm{d}}$ & $3.14 \pm 0.18^{\mathrm{b}}$ & $3.28 \pm 0.16^{\mathrm{d}}$ & $2.90 \pm 0.18^{\mathrm{a}}$ & $2.92 \pm 0.20^{\mathrm{b}}$ \\
\hline Root length (cm) & $14.00 \pm 1.38^{\mathrm{c}}$ & $14.10 \pm 1.32^{\mathrm{f}}$ & $14.40 \pm 2.34^{\mathrm{c}}$ & $14.60 \pm 1.36^{\mathrm{b}}$ & $13.30 \pm 1.32^{\mathrm{b}}$ & $13.70 \pm 1.38^{\mathrm{c}}$ \\
\hline Root weight (g), fresh & $6.80 \pm 0.68^{\mathrm{d}}$ & $6.70 \pm 0.64^{\mathrm{e}}$ & $7.50 \pm 0.60^{\mathrm{d}}$ & $7.40 \pm 0.64^{\mathrm{a}}$ & $7.00 \pm 0.66^{\mathrm{d}}$ & $7.20 \pm 0.68^{\mathrm{d}}$ \\
\hline Root weight (g), dry & $1.32 \pm 0.28^{\text {ef }}$ & $1.31 \pm 0.30^{\mathrm{d}}$ & $1.36 \pm 0.32^{\mathrm{e}}$ & $1.24 \pm 0.34^{\mathrm{e}}$ & $1.02 \pm 0.18^{\mathrm{b}}$ & $1.32 \pm 0.18^{\mathrm{e}}$ \\
\hline Shoot/Root ratio (length) & $3.77 \pm 2.60^{\mathrm{bf}}$ & $3.76 \pm 2.71^{\mathrm{b}}$ & $3.72 \pm 1.54^{\mathrm{a}}$ & $3.70 \pm 2.61^{\mathrm{b}}$ & $3.84 \pm 2.72^{\mathrm{c}}$ & $3.82 \pm 2.62^{\mathrm{b}}$ \\
\hline No. of branches & $5.40 \pm 1.18^{\mathrm{a}}$ & $5.60 \pm 0.96^{\mathrm{c}}$ & $5.70 \pm 0.88^{\mathrm{b}}$ & $5.80 \pm 1.40^{\mathrm{c}}$ & $4.90 \pm 1.34^{b}$ & $5.10 \pm 1.42^{\mathrm{c}}$ \\
\hline No. of pods & $16.00 \pm 2.10^{\mathrm{c}}$ & $18.50 \pm 2.24^{\mathrm{a}}$ & $19.00 \pm 2.78^{c}$ & $19.80 \pm 3.10^{\mathrm{d}}$ & $15.60 \pm 2.36^{\mathrm{d}}$ & $15.90 \pm 2.40^{\mathrm{d}}$ \\
\hline No. of seeds pod ${ }^{-1}$ & $8.10 \pm 1.42^{\mathrm{d}}$ & $8.30 \pm 1.46^{\mathrm{e}}$ & $8.50 \pm 1.46^{\mathrm{d}}$ & $8.70 \pm 1.38^{\mathrm{ae}}$ & $6.80 \pm 1.32^{\mathrm{a}}$ & $6.90 \pm 1.40^{\mathrm{a}}$ \\
\hline Weight of seeds (100 nos.) & $4.10 \pm 0.24^{\mathrm{e}}$ & $4.20 \pm 0.26^{\mathrm{d}}$ & $4.40 \pm 0.28^{\mathrm{e}}$ & $4.70 \pm 0.26^{\mathrm{e}}$ & $3.70 \pm 0.20^{\mathrm{b}}$ & $3.90 \pm 0.32^{\mathrm{b}}$ \\
\hline No. of nodule & $37.20 \pm 3.62^{b}$ & $38.40 \pm 4.12^{\mathrm{c}}$ & $39.80 \pm 3.24^{\mathrm{a}}$ & $40.40 \pm 4.50^{\mathrm{bc}}$ & $35.40 \pm 3.62^{\mathrm{c}}$ & $35.90 \pm 3.72^{\mathrm{d}}$ \\
\hline Weight of nodules $(\mathrm{g})$, fresh & $7.10 \pm 1.50^{\mathrm{d}}$ & $7.12 \pm 1.62^{\mathrm{b}}$ & $7.22 \pm 1.58^{\mathrm{b}}$ & $7.24 \pm 1.38^{\mathrm{c}}$ & $6.84 \pm 1.48^{\mathrm{d}}$ & $6.87 \pm 1.54^{\mathrm{e}}$ \\
\hline Weight of nodules (g), dry & $0.36 \pm 0.02^{\mathrm{a}}$ & $0.38 \pm 0.04^{\mathrm{ac}}$ & $0.39 \pm 0.03^{\mathrm{c}}$ & $0.40 \pm 0.04^{\mathrm{cd}}$ & $0.30 \pm 0.02^{\mathrm{e}}$ & $0.32 \pm 0.04^{\mathrm{f}}$ \\
\hline Population of AMF (spores $100 \mathrm{~g}^{-1}$ soil) & $92 \pm 5.4^{\mathrm{c}}$ & $94 \pm 5.2^{\mathrm{c}}$ & $95 \pm 4.8^{\mathrm{d}}$ & $95 \pm 4.2^{\text {ef }}$ & $86 \pm 5.4^{\mathrm{b}}$ & $88 \pm 5.2^{\mathrm{c}}$ \\
\hline Colonization of roots $(\%)$ & $68 \pm 4.4^{\mathrm{b}}$ & $70 \pm 4.5^{\mathrm{d}}$ & $75 \pm 4.4^{\mathrm{e}}$ & $77 \pm 4.6^{\mathrm{f}}$ & $66 \pm 3.8^{\mathrm{c}}$ & $68 \pm 4^{\mathrm{d}}$ \\
\hline Days of maturity & $69 \pm 4.4^{\mathrm{c}}$ & $72 \pm 4.5^{\mathrm{e}}$ & $73 \pm 4.8^{\mathrm{a}}$ & $75 \pm 4.2^{\mathrm{a}}$ & $68 \pm 3.4^{\mathrm{d}}$ & $68 \pm 4^{\mathrm{a}}$ \\
\hline Yield of grain $\left(\mathrm{kg} \cdot \mathrm{ha}^{-1}\right)$ & $580 \pm 18^{\mathrm{d}}$ & $588 \pm 20^{\mathrm{f}}$ & $594 \pm 14^{\mathrm{b}}$ & $598 \pm 20^{\mathrm{b}}$ & $612 \pm 22^{\mathrm{e}}$ & $622 \pm 24^{\mathrm{b}}$ \\
\hline $\mathrm{RGR}_{\mathrm{t}}\left(\right.$ day $\left.^{-1}\right)$ & $0.076 \pm 0.002^{\mathrm{e}}$ & $0.078 \pm 0.002^{\mathrm{c}}$ & $0.072 \pm 0.002^{\mathrm{c}}$ & $0.074 \pm 0.002^{\mathrm{c}}$ & $0.066 \pm 0.002^{\mathrm{d}}$ & $0.068 \pm 0.002^{\mathrm{c}}$ \\
\hline $\operatorname{RGR}_{\mathrm{s}}\left(\mathrm{day}^{-1}\right)$ & $0.076 \pm 0.002^{\mathrm{b}}$ & $0.078 \pm 0.002^{\mathrm{d}}$ & $0.072 \pm 0.003^{\mathrm{e}}$ & $0.074 \pm 0.002^{\mathrm{e}}$ & $0.064 \pm 0.002^{\mathrm{a}}$ & $0.068 \pm 0.002^{\mathrm{d}}$ \\
\hline $\operatorname{RGR}_{\mathrm{r}}\left(\mathrm{day}^{-1}\right)$ & $0.074 \pm 0.002^{\mathrm{a}}$ & $0.076 \pm 0.002^{\mathrm{a}}$ & $0.072 \pm 0.002^{\mathrm{d}}$ & $0.074 \pm 0.002^{\mathrm{d}}$ & $0.066 \pm 0.002^{\mathrm{c}}$ & $0.068 \pm 0.002^{\mathrm{a}}$ \\
\hline
\end{tabular}

Values indicate mean of five replicates $\pm \mathrm{SE}$. ${ }^{\mathrm{a}, \mathrm{b}, \mathrm{c}, \mathrm{d}, \mathrm{e}, \mathrm{f}}$ Mean data in each vertical row followed by different letters are significantly different $(\mathrm{P} \leq 0.05)$ as per Duncan's Multiple Range Test $(\mathrm{n}=5) . R G R_{t}, R G R_{s}$ and $R G R_{r}$ are Relative growth rate of total plant, shoot and root respectively determined within a period of growth of 45 days.

Parallel to this grain yield was maximum in Basanti followed by Canning and Kakdwip of South 24-Parganas (Table 2). Further it also revealed that maximum amount of grain (Table 3) was recovered in Saimalpur on North 24-Parganas whereas Kanthi had more yield (Table 4) than in Tamluk of East Medinipur districts.
Nodulation characteristics of $V$. radiata $L$. including the no. of nodules dry and fresh weight per plant after dual inoculation increases in all three districts i.e. South and North 24-Parganas and East Medinipur. Moreover, such improved features were better expressed in 2006 than in 2005 (Tables 2-4). 
Table 4. Effect of inoculation of salt tolerant Bradyrhizobium CAN-11 and G. mosseae BAS-I on the growth of V. radiata cv. B-1 in different experimental fields of East Medinipur during 2005 and 2006.

\begin{tabular}{|c|c|c|c|c|}
\hline \multirow{3}{*}{ Growth characteristics/plant ${ }^{-1}$} & \multicolumn{4}{|c|}{ Experimental fields of East Medinipur } \\
\hline & \multicolumn{2}{|c|}{ Kanthi } & \multicolumn{2}{|c|}{ Tamluk } \\
\hline & 2005 & 2006 & 2005 & 2006 \\
\hline Plant height $(\mathrm{cm})$ & $64.2 \pm 5.2^{\mathrm{a}}$ & $65.6 \pm 5.18^{\mathrm{b}}$ & $66.4 \pm 5.30^{\mathrm{c}}$ & $67.4 \pm 5.42^{\mathrm{a}}$ \\
\hline Total plant biomass (g), fresh & $19.8 \pm 2.16^{\mathrm{c}}$ & $20.2 \pm 2.42^{\mathrm{c}}$ & $20.8 \pm 2.14^{\mathrm{d}}$ & $21.4 \pm 2.32^{\mathrm{d}}$ \\
\hline Total plant biomass (g) Dry & $3.60 \pm 0.62^{\mathrm{d}}$ & $3.61 \pm 0.50^{\mathrm{d}}$ & $3.94 \pm 0.56^{\mathrm{a}}$ & $3.92 \pm 0.58^{\mathrm{b}}$ \\
\hline Shoot length $(\mathrm{cm})$ & $49.8 \pm 3.60^{\mathrm{a}}$ & $51.0 \pm 4.24^{\mathrm{e}}$ & $52.1 \pm 3.84^{\mathrm{b}}$ & $52.8 \pm 4.10^{\mathrm{c}}$ \\
\hline Shoot weight (g), fresh & $16.6 \pm 1.82^{\mathrm{b}}$ & $16.9 \pm 1.28^{\mathrm{a}}$ & $17.1 \pm 1.64^{\mathrm{c}}$ & $17.6 \pm 1.84^{\mathrm{d}}$ \\
\hline Shoot weight (g), dry & $2.99 \pm 0.42^{\mathrm{c}}$ & $3.1 \pm 0.48^{\mathrm{b}}$ & $3.3 \pm 0.52^{\mathrm{d}}$ & $3.2 \pm 0.59^{\mathrm{e}}$ \\
\hline Root length (cm) & $14.4 \pm 1.64^{\mathrm{d}}$ & $14.6 \pm 1.62^{\mathrm{d}}$ & $14.7 \pm 1.84^{\mathrm{e}}$ & $14.9 \pm 1.82^{\mathrm{f}}$ \\
\hline Root weight (g), fresh & $3.20 \pm 0.48^{\mathrm{a}}$ & $3.3 \pm 0.54^{\mathrm{c}}$ & $3.7 \pm 0.56^{\mathrm{c}}$ & $3.8 \pm 0.48^{\mathrm{b}}$ \\
\hline Root weight (g), dry & $0.61 \pm 0.06^{\mathrm{b}}$ & $0.63 \pm 0.04^{\mathrm{a}}$ & $0.64 \pm 0.04^{\mathrm{d}}$ & $0.72 \pm 0.06^{\mathrm{c}}$ \\
\hline Shoot/Root ratio (length) & $3.45 \pm 2.19^{\mathrm{c}}$ & $3.49 \pm 2.61^{b}$ & $3.64 \pm 2.08^{\mathrm{a}}$ & $3.61 \pm 2.25^{\mathrm{d}}$ \\
\hline No. of branches & $4.84 \pm 0.68^{\mathrm{d}}$ & $4.86 \pm 0.64^{\mathrm{d}}$ & $4.92 \pm 0.48^{\mathrm{b}}$ & $4.98 \pm 0.42^{\mathrm{e}}$ \\
\hline No. of pods & $21.2 \pm 2.18^{\mathrm{e}}$ & $22.4 \pm 2.42^{\mathrm{e}}$ & $22.8 \pm 2.42^{\mathrm{c}}$ & $23.1 \pm 2.46^{\mathrm{f}}$ \\
\hline No. of seeds pod ${ }^{-1}$ & $7.00 \pm 0.86^{\mathrm{a}}$ & $7.1 \pm 0.82^{\mathrm{d}}$ & $6.8 \pm 0.90^{\mathrm{d}}$ & $6.9 \pm 0.86^{\mathrm{d}}$ \\
\hline Weight of seeds (100 nos.) & $4.22 \pm 0.58^{\mathrm{b}}$ & $4.23 \pm 0.46^{\mathrm{b}}$ & $4.24 \pm 0.38^{\mathrm{a}}$ & $4.24 \pm 0.44^{\mathrm{e}}$ \\
\hline No. of nodule & $34.4 \pm 3.20^{\mathrm{c}}$ & $35.2 \pm 3.84^{\mathrm{c}}$ & $33.8 \pm 3.68^{\mathrm{b}}$ & $34.1 \pm 3.54^{\mathrm{c}}$ \\
\hline Weight of nodules $(\mathrm{g})$, fresh & $6.88 \pm 0.86^{\mathrm{d}}$ & $6.91 \pm 0.82^{\mathrm{d}}$ & $6.94 \pm 0.92^{\mathrm{c}}$ & $6.98 \pm 0.94^{\mathrm{d}}$ \\
\hline Weight of nodules (g), dry & $0.28 \pm 0.02^{\mathrm{e}}$ & $0.29 \pm 0.04^{\text {de }}$ & $0.30 \pm 0.06^{\mathrm{d}}$ & $0.31 \pm 0.06^{\mathrm{a}}$ \\
\hline Population of AMF (spores $100 \mathrm{~g}^{-1}$ soil) & $88 \pm 6.12^{\mathrm{b}}$ & $92 \pm 6.28^{\mathrm{ef}}$ & $90 \pm 6.40^{\mathrm{e}}$ & $94 \pm 6.48^{\mathrm{b}}$ \\
\hline Colonization of roots $(\%)$ & $72 \pm 4.80^{\mathrm{a}}$ & $76 \pm 5.26^{\mathrm{b}}$ & $74 \pm 5.24^{\mathrm{d}}$ & $78 \pm 5.84^{\mathrm{c}}$ \\
\hline Days of maturity & $78 \pm 4 c^{d}$ & $79 \pm 3.9^{c}$ & $69 \pm 5^{\mathrm{e}}$ & $70 \pm 5.0^{\mathrm{d}}$ \\
\hline Yield of grain $\left(\mathrm{kg} \cdot \mathrm{ha}^{-1}\right)$ & $590 \pm 20^{\mathrm{d}}$ & $598 \pm 12^{\mathrm{d}}$ & $586 \pm 22^{\mathrm{d}}$ & $594 \pm 24^{\mathrm{a}}$ \\
\hline$R G R_{t}\left(\right.$ day $\left.^{-1}\right)$ & $0.076 \pm 0.002^{\mathrm{e}}$ & $0.078 \pm 0.002^{\mathrm{e}}$ & $0.076 \pm 0.002^{\mathrm{a}}$ & $0.078 \pm 0.004^{\mathrm{e}}$ \\
\hline$R G R_{s}\left(\right.$ day $\left.^{-1}\right)$ & $0.076 \pm 0.002^{\mathrm{c}}$ & $0.076 \pm 0.002^{\mathrm{c}}$ & $0.074 \pm 0.004^{\mathrm{b}}$ & $0.078 \pm 0.002^{\mathrm{f}}$ \\
\hline$R G R_{r}\left(\right.$ day $\left.^{-1}\right)$ & $0.074 \pm 0.002^{\mathrm{b}}$ & $0.076 \pm 0.002^{\mathrm{a}}$ & $0.076 \pm 0.003^{\mathrm{c}}$ & $0.078 \pm 0.003^{\mathrm{c}}$ \\
\hline
\end{tabular}

Values indicate mean of five replicates $\pm \mathrm{SE}$. ${ }^{\mathrm{a}, \mathrm{b}, \mathrm{c}, \mathrm{d}, \mathrm{e}, \mathrm{f}}$ Mean data in each vertical row followed by different letters are significantly different $(\mathrm{P} \leq 0.05)$ as per Duncan's Multiple Range Test $(\mathrm{n}=5) . R G R_{t}, R G R_{s}$ and $R G R_{r}$ are Relative growth rate of total plant, shoot and root respectively determined within a period of growth of 45 days.

Table 5. Distribution of household according to annual income from present monocrop farming systems and introduced legume cultivation as second crop.

\begin{tabular}{|c|c|c|c|c|c|c|}
\hline \multirow{2}{*}{ Village } & \multicolumn{3}{|c|}{ Monocrop farming systems } & \multicolumn{3}{|c|}{ Legume cultivation as second crop } \\
\hline & No. of household & Annual income & $\%$ per household & No. of household & Annual income & $\%$ per household \\
\hline \multirow[t]{3}{*}{ Gabbani } & 168 & $\leq 15,000$ & 80.00 & - & $\geq 15,000$ & Nil \\
\hline & 31 & 15,000 to 50,000 & 14.76 & 190 & 15,000 to 50,000 & 90.48 \\
\hline & 11 & 50,000 to 100,000 & 5.23 & 20 & 50,000 to 100,000 & 9.52 \\
\hline \multirow[t]{3}{*}{ Barbari } & 131 & $\leq 15,000$ & 77.05 & - & $\geq 15,000$ & Nil \\
\hline & 33 & 15,000 to 50,000 & 19.41 & 160 & 15,000 to 50,000 & 94.12 \\
\hline & 6 & 50,000 to 100,000 & 3.52 & 10 & 50,000 to 100,000 & 5.82 \\
\hline
\end{tabular}

Villages: Gabbani and Barbari are from Canning district of South 24-Parganas, West Bengal. 
Table 6. The cost benefit ratio of cultivation of mung (V. radiata cv.B-1) in the farmers field.

\begin{tabular}{lcc}
\hline \multirow{2}{*}{ Particulars } & & V. radiata cv.B-1 \\
\cline { 2 - 3 } & Non-inoculated & Inoculated \\
\cline { 2 - 3 } & (Rs.) & 2100 \\
\hline Land preparation & 2100 & 700 \\
Sowing of seeds & 700 & 625 \\
Seed treatment & 750 & 250 \\
Cost of AM + Rhizobia inoculum & Nil & 1400 \\
Intercultural practices & 1400 & 1400 \\
Fertilizer (Basal dose N:P:K) & 1400 & 980 \\
Plant protection chemicals & 980 & 700 \\
Harvesting & 700 & 980 \\
Threshing \& Cleaning & 980 & 9135 \\
Total cost & 9010 & $825 \mathrm{Kg}$ \\
Yield/hectare & $750 \mathrm{Kg}$ & 20625 \\
Total sell @ $25 /$ Kg (grain) & 18750 & 11490 \\
Net profit & 9740 & \\
\hline
\end{tabular}

The level of mycorrhizal infection and density of AM spores in soil were better represented in the $2^{\text {nd }}$ year irrespective of the localities. However, it was maximum in East Medinipur district when compared to South and North 24-Parganas of West Bengal, India.

During the course of socio-economic study, a door to door survey was conducted over 210 and 170 families of Gabbani and Barbari villages of South 24-Parganas with a total population of 1695 and 1500 respectively. As the area is mono crop rice area, $77 \%-80 \%$ of household showed an average earning of Rs. 15,000 per annum, while only $3 \%-5 \%$ could have earned Rs. 50,000 100,000 per annum (Table 5).

In an attempt to introduce mung cultivation the cost benefit ratio was calculated considering the inoculation of AM fungus and rhizobial strains. Total cost of the inoculated crop was more than the non-inoculated one, but as the yield of inoculated crop was much more, it showed a net profit of $>10 \%$ over that of the uninoculated one (Table 6).

When this cropping system of pulse cultivation was introduced with salt tolerant inoculants, (rhizobium CAN-11 and AMF BAS-1) the socio-economic condition of the household farmers changed drastically. In both Gabbani and Barbari villages 90\% - 94\% household earned up to Rs. 50,000 per annum while 5.8\% - 9.5\% household could have earned up to Rs. 100,000 per annum (Table 5).

\section{DISCUSSION}

Salt salinity is known to affect drastically the growth and yield of various crop plants including the legumes [4]. However, improvements of legume crops by inoculation of rhizobia or AMF alone or in combination have been reported by several authors [18-23] under salt stress conditions. In this study, the best salt tolerant streptomycin resistant strain of Bradyrhizobium CAN-11 (specific for V. radiata L.) and Glomus mosseae BAS-1 were utilized for cultivation of $V$. radiata in pot culture and under field conditions.

The experimental data (Table 1 and Figures 1-3) revealed that combined inoculation of Bradyrhizobium CAN-11 and G. mosseae BAS-I increased the yield of V.radiata cv. B-I followed by single inoculation of Bradyrhizobium CAN-11 and G. mosseae BAS-I than the control uninoculated set. All the growth characteristics of $V$. radiata cv B-I were also improved simultaneously. Moreover, in V. radiata cv B-I the relative growth rate of total plant, shoot and root was also best in combined inoculation than the single inoculation. [24] reported that Rhizobium and Glomus sp. significantly increased the shoot and root fresh and dry weight, number of nodules in faba bean under saline condition. [25] reported that alleviation of salt stress in Lactuca sativa could be achieved by inoculation with Glomus sp. Similar beneficial effects of dual inoculation of Rhizobium/Bradyrhizobium and AMF were reported on the growth characteristics and yield of Medicago sativa [26], tomato [27], soybean [28], maize [29], cotton [22] and Lotus glaber [20].

Field experiments conducted in the saline soils of Basanti, Canning and Kakdwip of South 24-Parganas; Deuli, Kharampur and saimalpur of North 24-Parganas and Kanthi and Tamluk of East Medinipur districts using single and dual inoculation of Bradyrhizobium CAN-11 and G. mosseae BAS-I to V. radiata cv. B-I (Tables 2-4). It was revealed that the crop grew well and produced yields appreciably. The growth parameters like height of the plants shoot and root-fresh and dry weights, number of seeds per pods were increased under normal condi- 
tions. Similar observations have been reported in soybean [30], Sesbania aegyptiaca and S. grandiflora [21], Vigna radiata [31] and on Pisum sativum [32].

The beneficial effects of dual inoculation on the growth of $V$. radiata $\mathrm{L}$. might be due to reduction in $\mathrm{Na}$ uptake and increased uptake of $\mathrm{P}, \mathrm{N}$ and $\mathrm{Mg}$ and high content of chlorophyll in the inoculated plants which have played important roles in salinity alleviating mechanism of plants [21].

Further it was revealed that when the pulse cultivation was introduced in villages, namely Gabbani and Barbari of South 24-Parganas as a second crop utilizing salt tolerant Bradyrhizobium CAN-11 and G. mosseae BAS-I as the dual inoculation practices, the socio-economic conditions of the household farmers changed dramatically (Table 5). Similar beneficial report was reported by [33] have corroborated our findings with $V$. radiata and could find application in saline areas of West Bengal, India.

\section{ACKNOWLEDGEMENTS}

Authors are thankful to Prof. P. Bhattacherjee, Officer-in-Charge, Nodule Research Laboratory, Bidhan Chandra Krishi Viswavidyalaya, Mohanpur, Nadia, West Bengal, India for providing necessary facilities.

\section{REFERENCES}

[1] Dreschel, P., Gyiele, L., Kunze, D. and Cofie, O. (2001) Population density, soil nutrient depletion, and economic growth in sub-Saharan Africa. Ecology and Economics, 38, 251-258. doi:10.1016/S0921-8009(01)00167-7

[2] Kijne, J.W. (2005) Abiotic and water scarcity: Identifying and resolving conflicts from plant level to global level. Field Crops Research, 97, 3-18. doi:10.1016/j.fcr.2005.08.011

[3] Munns, R. (2002) Comparative physiology of salt and water stress. Plant, Cell and Environment, 25, 239-250. doi:10.1046/j.0016-8025.2001.00808.x

[4] Munns, R. (2005) Genes and salt tolerance: Bringing them together. New Phytologist, 167, 645-663. doi:10.1111/j.1469-8137.2005.01487.x

[5] Yadav, J.S.P., Bandopadhayay A.K. and Bandyopadhayay, B.K. (1993) Extent of coastal saline soils in India. Journal of the Indian Society of Coastal Agricultural Research, 1, 1-6.

[6] Cordovilla, M.P., Ocana, A., Ligero, F. and Lluch, C. (1995) Growth stage response to salinity in symbiosis Vicia faba Rhizobium-leguminosarum bv. Viciae. Plant Physiol, 14, 105-111.

[7] Cordovilla, M.P., Ocana, A., Ligero, F. and Lluch, C. (1995) Influence of host genotypes on growth, symbiotic performance and nitrogen assimilation in Faba bean (Vicia faba L.) under salt stress. Plant Soil, 172, 289-297. doi:10.1007/BF00011331

[8] Zahran, H.H. (1991) Conditions for successful Rhizobium-legume symbiosis in saline environments. Biology and Fertility of Soils, 12, 73-80. doi:10.1007/BF00369391
[9] Carvalho, L.M., Correia, P.M., Cacador, I., Ryel, R.J. and Martins-Loucao, M.A. (2003) Spatial variability of arbuscular mycorrhizal spores in two natural plant communities. Plant Soil, 251, 227-236. doi:10.1023/A:1023016317269

[10] Ruiz-Lozano, J.M. and Azcon, R. (2000) Symbiotic efficiency and infectivity of an autochthonous arbuscular mycorrhizal Glomus sp. from saline soils and Glomus deserticola under salinity. Mycorrhiza, 10, 137-43. doi:10.1007/s005720000075

[11] Aneja, K.R. (1996) Experiments in Microbiology, plant pathology, tissue culture and mushroom cultivation. 2nd Edition, Wishwa Prakashan, New Delhi, 130-132.

[12] Ames, P. and Bergman, R. (1981) Competitive advantage provided by bacterial motility in the formation of nodules by Rhizobium melitoli. Journal of Bacteriology, 148, 728-729.

[13] Plenchette, C., Perrin, R. and Duvert, P. (1989) The concept of soil infectivity and methods for its determination as applied to endomycorrhiza. Canadian Journal of Botany, 67, 112-115. doi:10.1139/b89-016

[14] Phillips, J.M. and Hayman, D.S (1970) Improved procedure for clearing roots and staining parasitic and vesicular-arbuscular mycorrhizal fungi for rapid assessment of infection. Transactions of the British Mycological Society, 55, 158-161. doi:10.1016/S0007-1536(70)80110-3

[15] Giovannetti M. and Mosse, M. (1980) An evaluation of techniques for measuring vesicular arbuscular mycorrhizal infection in roots. New Phytologist, 84, 489-500. doi:10.1111/j.1469-8137.1980.tb04556.x

[16] Daniels, B.A. and Skipper, H.A. (1982) Methods for the recovery and quantitative estimation of propagules from soil. In: Schenck, N.C., Ed., Methods \& Principles of Mycorrhizal Research, American Phytopathological Society, St. Paul, 29-35.

[17] Duncan, D.B. (1955) Multiple range and multiple F test. Biometrics, 11, 1-42. doi:10.2307/3001478

[18] Sheng, M., Tang, M., Chen, H. and Yang, B. (2008) Influence of arbuscular mycorrhizae on photosynthesis and water status of maize plants under salt stress. Mycorrhiza, 18, 287-296. doi:10.1007/s00572-008-0180-7

[19] Zuccarini, P. (2007) Mycorrhizal infection ameliorates chlorophyll content and nutrient uptake of lettuce exposed to saline irrigation. Plant, Soil and Environment, 53, 283-289.

[20] Mendoza, R., Escudero V. and Gracia, H. (2005) Plant growth, nutrient acquisition and mycorrhizal symbioses of a waterlogging tolerant legume (Lotus glaber Mill.) in a saline-sodic soil. Plant and soil, 275, 305-315. doi:10.1007/s11104-005-2501-3

[21] Giri, B. and Mukerji, K.G. (2004) Mycorrhizal inoculan alleviates salt stress in Sesbania aegyptiaca and Sesbania grandiflora under field conditions evidence for reduced sodium and improved magnesium uptake. Mycorrhiza, 14, 307-312. doi:10.1007/s00572-003-0274-1

[22] Tian, C.Y., Feng, G., Li, X.L. and Zhang, F.S. (2004) Different effects of arbuscular mycorrhizal fungal isolates from saline or non-saline soil on salinity tolerance of plants. Applied Soil Ecology, 26,143-148. doi:10.1016/j.apsoil.2003.10.010

[23] Quilambo, O.A. (2003) The vesicular-arbuscular mycorrhi- 
zal simbiosis. African Journal of Environmental, 2, 539546.

[24] Ahmed, A.E. and Elsheikh, E.A.E. (1998) Effects of biological and chemical fertilizers on growth and symbiotic properties of faba bean (Vicia faba) under salt stress. Journal of Agricultural Sciences, 6, 150-166.

[25] Ruiz-Lozano, J.M. and Azcon, R. (1996) Mycorrhizal colonization and drought stress as factors affecting nitrate reductase activity in lettuce plants. Agriculture, Ecosystems \& Environment, 60, 175-181. doi:10.1016/S0167-8809(96)01074-2

[26] Azcon, R. and El-Atrash, F. (1997) Influence of arbuscular mycorrhizae and phosphorus fertilization on growth, nodulation and $\mathrm{N}_{2}$ fixation $\left({ }^{15} \mathrm{~N}\right)$ in Medicago sativa at four salinity levels. Biology and Fertility of Soils, 24, 81-86. doi:10.1007/BF01420225

[27] Al-Karaki, G.N. (2000) Growth of mycorrhizal tomato and mineral acquisition under salt stress. Mycorrhiza, 10, 51-54. doi:10.1007/s005720000055

[28] Ruiz-Lozano, J.M., Callados C., Barea, J.M. and Azcon, R. (2001) Arbuscular mycorrhizal symbiosis can alleviate drought-induced nodule senescence in soybean plants. New Phytologist, 151, 493-502. doi:10.1046/j.0028-646x.2001.00196.x
[29] Feng, G., Zhang, F.S., Li, L.X., Tian, C.Y., Tang, C. and Rengel, Z. (2002) Improved tolerance of maize plants to salt stress by arbuscular mycorrhiza is related to higher accumulation of soluble sugars in roots. Mycorrhiza, 12, 185-190. doi:10.1007/s00572-002-0170-0

[30] Bagyaraj, D.J., Manjunath, A. and Patil, R.B. (1979) Interaction between a vesicular-arbuscular mycorrhiza and Rhizobium and their effects on soybean in the field. New Phytologist, 82, 141-145. doi:10.1111/j.1469-8137.1979.tb07568.x

[31] Hazarika, D.K., Das, K.K., Dubey, L.N. and Phookan, A. K. (2000) Effect of vesicular arbuscular mycorrhizal (VAM) fungi and Rhizobium on growth and yield of green gram. Vigna radiata L.Witzeck). Journal of Mycology and Plant Pathology, 30, 424-426.

[32] Borucki, W. and Sujkowska, M. (2008) The effect of sodium chloride-salinity upon growth, nodulation and root nodule structure of pea (Pisum sativum L.) plants. Acta Physiologiae Plantarum, 30, 293-301. doi:10.1007/s11738-007-0120-8

[33] Jha, S.K., Bandopadhayay, B.K., Maji, B. and Tripathi, S. (2003) Socioeconomic profile of typical coastal village of sunderbans. Journal of the Indian Society of Coastal Agricultural Research, 21, 45-48. 